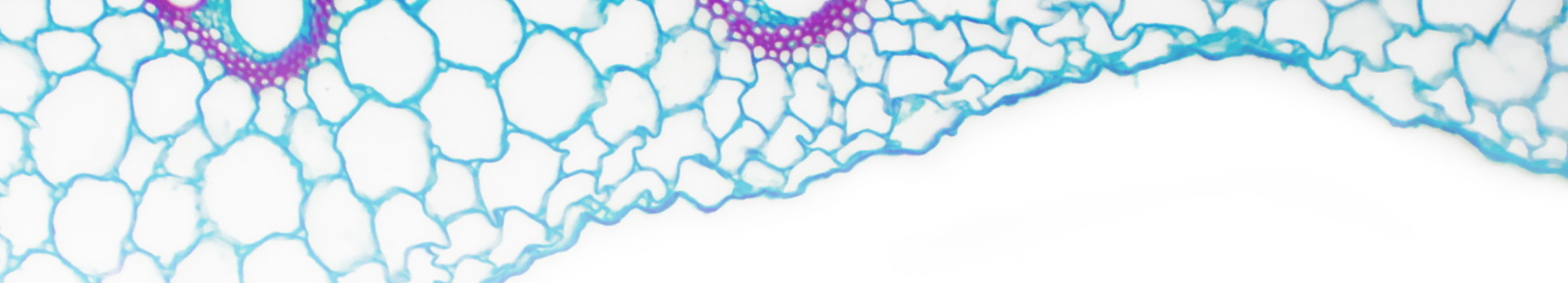

AMA Journal of Ethics ${ }^{\circledR}$

December 2020, Volume 22, Number 12: E1004-1009

\title{
CASE AND COMMENTARY: PEER-REVIEWED ARTICLE \\ Should a Patient Who Is Pregnant and Brain Dead Receive Life Support, Despite Objection From Her Appointed Surrogate?
}

Daniel Sperling, SJD

\begin{abstract}
This article considers whether and when a physician is obligated to offer life support to the point of fetal viability to a patient who is brain dead and pregnant. Lack of ethical, legal, and clinical consensus about best practice in managing this kind of case; a poor clinical evidence base; and the fact that offering life support violates the patient's autonomy and human dignity, as expressed in her advance directive, are sources of ethical, legal, and clinical complexity analyzed here.
\end{abstract}

To claim one AMA PRA Category 1 CreditTM for the CME activity associated with this article, you must do the following: (1) read this article in its entirety, (2) answer at least 80 percent of the quiz questions correctly, and (3) complete an evaluation. The quiz, evaluation, and form for claiming AMA PRA Category 1 CreditTM are available through the AMA Ed HubTM.

Case

BR is a 28-year-old woman in Nevada who is 10 weeks pregnant. She was comatose on arrival to the emergency department and found to have a ruptured arteriovenous malformation (AVM), a tangle of vessels in the brain. BR had right corneal and gag reflexes and was over-breathing the ventilator. Due to the severity of her condition, BR's care team deferred treating her $\mathrm{AVM}^{1}$ to see if she would improve neurologically. They placed an external ventricular drain in BR's head, and after 2 days, bright red blood filled the drain. A repeat scan showed that her AVM had re-bled.

Upon examination, BR no longer has any evidence of brain activity. $\mathrm{Dr} \mathrm{N}$, the attending physician, determines her to be dead using the American Academy of Neurology 2010 standards. ${ }^{2,3}$ After discussion with a hospital administrator, Dr N tells BR's husband, J, that BR's organs will continue to be perfused since Nevada's Uniform Determination of Death Act states that organ support will not be withheld or withdrawn from a pregnant woman if it is "probable that the fetus will develop to the point of live birth with continued application of organ-sustaining treatment." 4

J objects, "My wife has an advance directive stating she does not want to depend on machines to stay alive, so it would be disrespectful to her to have machines keep her alive for the sake of the baby's reliance on her organs. As hard as it is," J confesses, "I don't feel right using my wife's body as an incubator if she's not alive." 
Feeling sympathy for J's views and an obligation to comply with state law, $\mathrm{Dr} N$ wonders how to respond.

\section{Commentary}

Brain death during pregnancy is an exceedingly rare event but one that has significant practical, ethical, and legal implications. ${ }^{5}$ In this case, BR, a pregnant woman, has been determined to be brain dead. The medical practitioners want to follow the local law, which mandates artificially maintaining the somatic functions of a woman in her stage of pregnancy. BR's husband feels that maintaining BR on machines is disrespectful and in violation of her wishes expressed in an advance directive, which states that she does not want life support. Hence, what is being proposed is continuing organ support for a person who is dead, with the intent to hopefully allow the fetus to complete gestation and be delivered, despite the mother's wishes seemingly to the contrary. The medical team is thus confronted with an ethical and professional dilemma, which is complicated by limited clinical data and legal challenges.

\section{Ethical Analysis}

Respect for bodily autonomy. Professional organizations, such as the American College of Obstetricians and Gynecologists and the International Federation of Gynecology and Obstetrics, hold that respecting the rights of the pregnant woman who is the primary patient should take precedence over the delivery of the fetus in ethical deliberations whenever legally possible.5,6 One might argue that keeping BR under life support against her previously expressed wishes would amount to objectifying her and treating her as a consumable body. ${ }^{7}$ Seen this way, a woman serves as a mere means to preserve life, especially if she is kept on life support against her wishes in the early stages of pregnancy when the fetus is less likely to survive and hence the state's interest in the life of the fetus should not override the woman's right to personal autonomy and dignity. ${ }^{6}$ Moreover, subjecting BR to life support against her wishes would undermine her constitutional right to make effective decisions about her own body. ${ }^{8}$ It would also violate her right to bodily integrity ${ }^{9}$ and the physicians' duty to treat her in a respectful and humane way, ${ }^{10}$ including when she is (a) dead (patient). ${ }^{11}$

Right to refuse treatment. In addition, ignoring a woman's previously expressed wish not to be dependent on life support just because she is pregnant infringes on her elementary right to refuse medical treatment or any form of medical intervention, 12 thereby treating her unjustly and unfairly. Such a practice should therefore be regarded discriminatory. 12 In the context of this case, it also violates her constitutional right to privacy and to terminate pregnancy, more specifically. ${ }^{8}$

Respect for symbolic existence. In addition, one can argue that if mechanical ventilation violates a previously living pregnant woman's right to personal autonomy and a braindead pregnant woman's right to respect and human dignity, it affects her symbolic existence, since being viewed as a "ventilated corpse" shapes the way she is perceived and imagined by others. In this respect, the violation of one's right not to be perceived in disrespectful ways by others applies following the death of a person as much as it applies while she is alive.13 Moreover, promoting actions to save the life of a fetus in the face of death reflects a troubling shift from accepting the symbolic continuity of the dead woman with the living woman to re-initiating the woman's "real" life through some potential life. ${ }^{14}$ 
Best interests of the child. Maintaining BR on life-support until delivery-if indeed a successful pregnancy can be assured-is a deliberate act of planned orphanhood. One should question whether it is in the best interest of a child to live in and serve as the memory of her dead and artificially maintained mother. ${ }^{15}$ Although there is little research examining the effect of such a practice on the well-being of the future child, it is argued in the case of posthumous reproduction that extensive psychological counseling should take place 16 and that due consideration must be given to the psychological well-being of the future child.

Interests of the father. Other than the rights and interests of the brain-dead pregnant woman and the fetus, this case also raises concerns as to the role of BR's husband in advancing BR's interests. A challenging component of this case involves the views and interests of BR's husband as the father of this fetus. It can be argued that the decision as to whether to continue to maintain BR on life support for the best interest of the fetus should be determined with reference to the patient about whom the decision is madenamely, BR-regardless of other parties' interests in that decision. Assuming there are 2 patients in this case (BR and the fetus), the father may be called upon to reflect upon the best course of action pertaining to their interests and not his own. ${ }^{11}$ In this case, BR's interests seem to correspond to BR's previous wish not to be artificially maintained under life support.

\section{Clinical Evidence}

The ethical challenges discussed above are complicated by limited clinical data pertaining to cases of brain death during pregnancy. It is reasonable to argue that, in principle, the woman's rights and interests should be subordinated to those of the fetus only when there is a realistic prospect of fetus survival and possibly only when a fetus' survival entails tolerable complications, illness, or disability. While reports of such cases are limited, some important insights can still be made.

First, because there is limited experience with and scarce reporting of cases, there is no consensus as to the best practice to manage such cases. ${ }^{17}$ A 2016 review of brain death protocols in US hospitals revealed that the vast majority of them (93.8\%) offer no guidance about fetal management following maternal brain death. ${ }^{18}$ More disturbingly, $99 \%$ of them do not refer to the person who is responsible for making decisions for the fetus. ${ }^{18}$

Second, evidence suggests that the effectiveness of maintaining a brain-dead pregnant woman on life support to allow continued fetal development depends on the gestational age and physiological health of the fetus-specifically, lung maturity-at the time of brain death. Most documented cases show that gestation could be prolonged for 14 to 45 days (2-6 weeks). ${ }^{19}$ A literature review of 30 cases published between 1982 and 2010 revealed that only 12 resulted in the delivery of viable infants. ${ }^{20}$ These data should call into question the assumption that the state might be acting to promote the interest of potential life when the potential for life might not be significantly high, given the early stage of pregnancy during which the medical intervention would have to take place.

\section{Legal Challenge}

While the ethical analysis and the clinical data discussed in this article lead to the conclusion that the previously expressed wishes of BR should be upheld, with the result that life support would be discontinued, such an action allegedly goes against Nevada state law. BR's case therefore not only reflects a situation in which the law cannot be 
supported on moral and ethical grounds, but also serves as an example of the more general phenomenon in which the law's interference with and shaping of bioethical issues results in serious threats to important interests reflected in these issues. ${ }^{21}$

It could be argued that, while the purpose of this law is to preserve life and protect the state's interest in the fetus, it does not extend to maintaining a pregnancy over the objections of the patient and her family members. Yet the Nevada law characterizes the determination of death as well as the management of death during pregnancy as a clinical decision, thereby ignoring the doctrine of informed consent and the ethical duty to respect the patient and her beliefs. ${ }^{22}$ One can further argue that the rationale for this law is to provide procedural and substantive rules for making treatment decisions when there are no previous directives from the patient or her guardian. This is not the case here.

An additional argument raised in a similar case falling under a comparable law in Texas holds that while the language of such a law may seem mandatory, the law nonetheless does not force medical practitioners to act in accordance with it. ${ }^{23}$ By this reasoning, health care practitioners may choose not to comply with this law. In such a case, their only sanction is that they will be denied legal immunity that could have been secured had they followed the law. However, if physicians enforce BR's previous directive to not maintain her under life support, they might still enjoy legal immunity under state law and case law upholding the legal validity of advance directives more generally, assuming such laws do not hold constitutionally valid exceptions.

For these reasons, it is argued here, as it has been argued in a more detailed analysis elsewhere, ${ }^{24}$ that if the pregnant woman gave explicit directions about foregoing life support in case of loss of competency, physicians should follow her instructionsespecially if the fetus is in its first or second trimester-and no state interest in protecting potential life should apply before that time. Any law that specifies otherwise might not be justified under reasonable ethical or constitutional analysis.

\section{References}

1. Beecher JS, Lyon K, Ban VS, et al. Delayed treatment of ruptured brain AVMs: is it ok to wait? J Neurosurg. 2018;128(4):999-1005.

2. Wijdicks EFM, Varelas PN, Gronseth GS, Greer DM. Evidence-based guideline update: determining brain death in adults: report of the Quality Standards Subcommittee of the American Academy of Neurology. Neurology. 2010;74(23):1911-1918.

3. Greer DM, Shemie SD, Lewis A. Determination of brain death/death by neurologic criteria: the World Brain Death Project. JAMA. 2020;324(11):10781097.

4. Nevada State Legislature. Chapter 451-dead bodies. https://www.leg.state.nv.us/NRS/NRS-451.html\#NRS451Sec008. Accessed July $7,2020$.

5. Committee on Ethics, American College of Obstetricians and Gynecologists. Committee opinion no. 617: end-of-life decision making. Obstet Gynecol. 2015;125(1):261-267.

6. Dickens B; FIGO Committee for the Ethical Aspects of Human Reproduction and Women's Health. Brain death and pregnancy. Int J Gynaecol Obstet. 2011;115(1):84-85.

7. Suen A. The construction of a consumable body. Fem Philos Q. 2019;5(1):1. 
8. Humphrey WA. But I'm brain-dead and pregnant: advance directive pregnancy exclusions and end-of-life wishes. William Mary J Women Law. 2015;21(3):669698.

9. Lewis A, Varelas P, Greer D. Pregnancy and brain death: lack of guidance in US hospital policies. Am J Perinatol. 2016;33(14):1382-1387.

10. Sperling D. Maternal brain death. Am J Law Med. 2004;30(4):453-500.

11. Heywood R. Live or let die?: fine margins between life and death in a brain-dead pregnancy. Med Law Rev. 2017;25(4):628-653.

12. Sperling D. Do pregnant women have (living) will? J Health Care Law Policy. 2005;8(2):331-342.

13. Sperling D. Posthumous Interests: Legal and Ethical Perspectives. Cambridge, UK: Cambridge University Press; 2008.

14. Katz 0 , Hashiloni-Dolev Y. (Un) natural grief: novelty, tradition and naturalization in Israeli discourse on posthumous reproduction. Med Anthropol Q. 2019;33(3):345-363.

15. Landau R. Planned orphanhood. Soc Sci Med. 1999;49(2):185-196.

16. Lawson AK, Zweifel JE, Klock SC. Blurring the line between life and death: a review of the psychological and ethical concerns related to posthumous-assisted reproduction. Eur J Contracept Reprod Health Care. 2016;21(5):339-346.

17. Rachid MM, Sehring M, Taneja D, Nair D. Doing more harm than good? Sustaining life support in maternal brain death during pregnancy. Am J Respir Crit Care Med. 2019;199:A6668.

18. Lewis A, Varelas P, Greer D. Pregnancy and brain death: lack of guidance in US hospital policies. Am J Perinatol. 2016;33(14):1382-1387.

19. Spike JP. Pregnancy, brain death, and posthumous motherhood: a provisional policy proposal. Am J Bioeth. 2014;14(8):48-50.

20. Esmaeilzadeh M, Dictus C, Kayvanpour E, et al. One life ends, another begins: management of a brain-dead pregnant mother-a systematic review. BMC Med. 2010;8:74.

21. Sperling D. Law and bioethics: a rights-based relationship and its troubling implications. Curr Leg Issues. 2008;11:52-78.

22. Yanke G, Rady MY, Verheijde JL. Ethical and legal concerns with Nevada's brain death amendments. J Bioeth Inq. 2018;15(2):193-198.

23. Mayo TW. Brain-dead and pregnant in Texas. Am J Bioeth. 2014;14(8):15-18.

24. Sperling D. Management of Post-mortem Pregnancy: Legal and Philosophical Aspects. Aldershot, UK: Ashgate; 2006.

Daniel Sperling, SJD is an associate professor of bioethics in the Department of Nursing at the University of Haifa in Israel. He holds an LLB degree and a BA degree in philosophy from the Hebrew University of Jerusalem and an LLM degree (Collaborative Specialization in Bioethics) and an SJD degree from the University of Toronto. He is the author of 3 books: Suicide Tourism: Understanding the Legal, Philosophical and Sociopolitical Dimensions (Oxford University Press, 2019), Posthumous Interests: Legal and Ethical Perspectives (Cambridge University Press, 2008), and Management of Postmortem Pregnancy: Legal and Philosophical Aspects (Ashgate, 2006), as well as numerous articles and book chapters in the area of law and bioethics. 


\section{Editor's Note}

The case to which this commentary is a response was developed by the editorial staff.

\section{Citation}

AMA J Ethics. 2020;22(12):E1004-1009.

DOI

10.1001/amajethics.2020.1004.

\section{Conflict of Interest Disclosure}

The author(s) had no conflicts of interest to disclose.

The people and events in this case are fictional. Resemblance to real events or to names of people, living or dead, is entirely coincidental. The viewpoints expressed in this article are those of the author(s) and do not necessarily reflect the views and policies of the AMA.

Copyright 2020 American Medical Association. All rights reserved. ISSN 2376-6980 